Seção Temática: Os Recursos Públicos em Disputa

Volume 11 - $2021 \mid$ n. 24

\title{
A Captação de Recursos Próprios pelas Universidades Públicas Federais: autonomia ou mercantilização?
}

\author{
Eduardo Ferreira da Silva Caetano \\ Universidade de São Paulo (USP), São Paulo/SP - Brasil \\ Ivete Maria Barbosa Madeira Campos \\ Universidade de Brasília (UnB), Brasília/DF - Brasil \\ Vilma Pereira Cavalcanti \\ Universidade Federal de Lavras (UFLA), Lavras/MG - Brasil
}

\section{Resumo}

As universidades públicas federais brasileiras oferecem ensino, conhecimento e tecnologia à sociedade. Este artigo comparou a mercantilização da educação superior pública entre Brasil, Chile, Estados Unidos da América e Portugal, bem como examinou a gestão financeira das despesas empenhadas, liquidadas e pagas das arrecadações de receitas próprias oriundas de prestação de serviços entre 2010 e 2020 dessas instituições no Brasil. Utilizou-se a abordagem quantitativa. Concluiu-se que a autonomia é um direito constitucional das universidades brasileiras e que há tentativa de mercantilização da educação superior pública federal. Este artigo desvelou que, desde 2016, os recursos discricionários de fonte tesouro e verbas de capital de fontes próprias diminuíram, contudo, as universidades usam fontes próprias e fundações de apoio para complementar seus recursos.

Palavras-chave: Autonomia Universitária. Universidades Federais. Mercantilização. Receitas Próprias.

\section{Fundraising of Own Resources by Federal Public Universities: autonomy or commodification?}

\section{Abstract}

Brazilian federal public universities offer education, knowledge, and technology to society. This article compared the commodification of public higher education between Brazil, Chile, the United States of America, and Portugal, as well as examined the financial management of committed, settled, and paid expenses of own revenue collections arising from the provision of services between 2010 and 2020 of these institutions in Brazil. A quantitative approach was used. It was concluded that autonomy is a constitutional right of Brazilian universities and that there is an attempt to commodify federal public higher education. This article unveiled that, since 2016, discretionary treasury resources and equity funds from own sources have decreased, however, universities use their own sources and supporting foundations to supplement their resources.

Keywords: University Autonomy. Federal Universities. Commodification. Own Revenue. 
A Captação de Recursos Próprios pelas Universidades Públicas Federais

\section{Introdução}

A universidade é inventora eficaz, criativa e agente de transferência de conhecimento, tecnologia e capital social (AROCENA; SUTZ, 2021). As universidades exercem três missões: ensino, pesquisa e extensão (FERRARIS; BELYAEVA; BRESCIANI, 2020). No entanto, para que essas missões sejam cumpridas, as universidades públicas necessitam desenvolver a versatilidade para captar recursos econômicos em operação em seus campi (BELYAEVA et al., 2018).

Para desempenhar essa gama de atividades precisam de financiamento (ERNSTE, 2007). A depender do formato de financiamento vigente em seus países de origem, as universidades públicas contam com receitas de fonte pública, filantropia, receitas de comercialização de serviços ou cobram mensalidades e taxas como formas para promover e financiar suas atividades (LIEFNER, 2003; CONTRERAS; LOZANO, 2020; HSU et al., 2021).

No entanto, cada vez mais universidades públicas enfrentam o problema crítico e histórico de necessidade de mais recursos (WANG, 2019). Frente à escassez de financiamentos, algumas dessas instituições selecionam e priorizam projetos e planos de pesquisas científicas de interesse de empresas privadas com o discurso de arrecadar mais recursos para o autofinanciamento (SHEN, 2020). No caso brasileiro, isso se constitui em um processo contraditório, uma vez que o espaço e mão de obra das universidades públicas federais seriam usados para prestar serviços para organizações de direito privado. Os contratos entre universidades públicas federais e empresas privadas possibilitam que resultados de pesquisas sejam exclusivos do contratante, contradizendo a finalidade da instituição de ensino público de produção de conhecimento cientifico e tecnológico para o bem público e coletivo (SGUISSARDI, 2008).

Essa relação entre universidade pública federal e empresa privada tem gerado questionamentos por parte dos órgãos de controle externo e de integrantes acadêmicos. Estes são contrários à captação de recursos financeiros oriundos de empresas privadas para financiar suas pesquisas em universidades públicas federais, porque acreditam que há interferência na autonomia didático-científica das universidades federais (STEINER et al., 2013; ANAFINOVA, 2020).

Esta pesquisa busca preencher a lacuna de estudo comparativo sobre a mercantilização na educação superior pública entre o caso brasileiro com países latino-americanos e desenvolvidos e também examinar a execução das despesas e as receitas das universidades federais brasileiras que utilizam sua autonomia para prestar serviços ou pesquisas para o setor privado como forma de arrecadar verbas financeiras (CARVALHO, 2013; RAUDLA; KARO; VALDMAA; KATTEL, 2015).

A pergunta norteadora deste artigo é: como as universidades públicas federais, independentemente da forma de financiamento nas economias pesquisadas, têm se posicionado ante a tendência de direcionamento da autonomia para a mercantilização do ensino superior público?

O presente estudo tem o objetivo de comparar a mercantilização na educação superior pública entre o caso brasileiro e países latino-americanos e desenvolvidos, desvelar se há mercantilização da educação superior pública; verificar o sentido e a relação de autonomia universitária e mercantilização com captação de recursos próprios e, por fim, examinar a 
A Captação de Recursos Próprios pelas Universidades Públicas Federais

execução financeira do ciclo da despesa orçamentária (empenho ${ }^{1}$, liquidado ${ }^{2}$ e pago ${ }^{3}$ ) das fontes próprias das universidades federais brasileiras entre 2010 e 2020.

Este artigo utiliza o desenho da abordagem quantitativa, pois acredita-se que o estudo quantitativo pode gerar questões para serem aprofundadas durante a análise dos fatos investigados (MINAYO; SANCHES, 1993, p. 247).

Para tanto, buscou-se na literatura descrições e dados de financiamento da educação superior no Brasil e em países latino-americanos e desenvolvidos. No caso das universidades públicas federais brasileiras, optou-se por dados primários, cruzando-se os dados das arrecadações de fonte própria das universidades federais brasileiras entre 2010 e 2020 .

Os dados quantitativos de fonte tesouro e fonte própria das universidades federais brasileiras foram obtidos no Sistema Integrado da Administração Financeira (SIAFI), site do governo federal. Por serem bases extensas e complexas, foram tratados e sintetizados para melhor apresentação.

As análises e os resultados desta pesquisa apontaram diminuição de recursos para as despesas discricionárias das universidades federais, que passaram a buscar complementação de verbas fosse com esforço próprio ou por meio de suas fundações de apoio. No final, discute-se as relações entre os resultados e suas implicações para a agenda de pesquisa.

Sob essa perspectiva, o artigo é composto, além da introdução e considerações finais, por quatro seções. A primeira trata da abordagem e os procedimentos metodológicos. $\mathrm{Na}$ segunda, aborda-se o sentido de autonomia universitária e mercantilização da educação superior. A terceira, apresenta a escolha dos países latino-americano e desenvolvidos e faz o comparativo sobre o financiamento e mercantilização da educação superior pública desses países e o caso brasileiro. Na quarta, analisa-se a gestão estratégica e financeira das fontes próprias arrecadadas pelas universidades públicas federais brasileiras no período de 2010 a 2020.

\section{Abordagem e os procedimentos metodológicos}

Este estudo utiliza a pesquisa de abordagem quantitativa, que propicia melhor assimilação de dados e informações resultante dos fatos investigados (CRESWELL; PLANO CLARK; 2011). Este método também viabiliza a exposição, análise e explicação dos dados numéricos, visto que, alguns problemas se aproximam mais do método e tratamento quantitativo do que outros métodos (BACHINI; CHICARINO, 2018). Os dados foram organizados e classificados de forma sistemática, passando pelas fases de seleção, codificação e tabulação (PRODANOV; FREITAS, 2013).

1 Empenho seria o ato oriundo de autoridade competente que gera para o Estado a obrigação de pagamento pendente ou não de implemento de condição (Giacomoni, 2012).

2 Liquidado se dá após o empenho, seria a averiguação do direito adquirido pelo credor, tendo como suporte os títulos e documentos comprobatórios do respectivo crédito (Giacomoni, 2012).

3 Pago acontece após a liquidação, que seria o repasse do recurso financeiro ao credor do Estado, suprimindo, portanto, o débito ou obrigação (Giacomoni, 2012). 
A Captação de Recursos Próprios pelas Universidades Públicas Federais

Os dados foram extraídos de sistemas oficiais do governo federal, sobretudo o Sistema SIAFI, pois a metodologia quantitativa reporta-se ao conhecimento das técnicas para investigar e organizar os dados publicamente disponíveis (BACHINI; CHICARINO, 2018).

Os elementos ano, unidade orçamentária, resultado primário, fonte de governo, grupo de despesas, dotação inicial ${ }^{4}$, despesas empenhadas, liquidadas e pagas, foram selecionados para as extrações de relatórios como parâmetros de obtenção de dados. Foram estudadas as despesas obrigatória, discricionária e recursos próprios. Os dados utilizados por este artigo podem ser replicados em relatórios disponíveis pelo Portal da Transparência e Siga Brasil.

Obtiveram-se relatórios extensos e complexos que foram sintetizados por ferramentas como tabelas dinâmicas e planilhas eletrônicas do Excel com o fim de viabilizar a interpretação e análise dos dados. Os valores das tabelas tiveram correção monetária pelo Índice Nacional de Preços ao Consumidor Amplo (IPCA) do Instituto Brasileiro de Geografia e Estatística (IBGE).

O período entre 2010 e 2020 foi escolhido porque, em 2010, houve a publicação do Decreto $n^{0} 7.423 / 2010$, que remodelou as fundações de apoio ${ }^{5}$ para fazer maior arrecadação ou mercantilizar pesquisas realizadas dentro das universidades públicas federais (CARVALHO, 2013). Assim, tornou-se interessante acompanhar o estudo de 2010 em diante, já que as universidades públicas federais usam as fundações para arrecadar recursos financeiros. Assim, oportunizou-se apontar o processo de arrecadação dessas fundações nas arrecadações de fontes próprias das universidades federais.

\section{Significado de autonomia universitária e mercantilização}

Desde a "Idade Média, até os dias de hoje, a liberdade e a autonomia fazem parte do conceito de universidade" (DIAS, 2017, p. 121). Nesse sentido, autonomia "não é um fim em si mesmo, mas condição necessária para a concretização dos fins da universidade" (FÁVERO, 2010, p. 79).

Para Ranieri (2013), autonomia "[...] exprime a ideia de 'direção própria', dentro dos limites preestabelecidos complexo de poderes e funções necessário e suficiente para justificar a existência de instituições não soberanas dotadas de capacidade autonormativa" (RANIERI, 2013, p. 37).

O art. 207 da Constituição Federal (CF) de 1988 fixou que "[...] as universidades gozam de autonomia didático-científica, administrativa e de gestão financeira e patrimonial, e obedecerão ao princípio de indissociabilidade entre ensino, pesquisa e extensão". Para Ranieri e Lutaif (2019), esse artigo ainda não foi efetivado de fato, uma vez que as universidades federais continuam sendo regulamentadas por normas legais menores emanadas por órgãos do governo federal como portarias. Esse normativo não fixou regime de caixa único, contingenciamento de despesas, peso da burocracia estatal e valor de financiamento que interfiram na eficácia da autonomia universitária (RANIERI; LUTAIF, 2019).

\footnotetext{
4 Dotação inicial é o valor previsto ao orçamento inicial da Lei Orçamentária Anual (LOA) para cada órgão público (Giacomoni, 2012).

5 Para maiores informações, ver estudo de Alves e Azevedo (2006).
} 
A Captação de Recursos Próprios pelas Universidades Públicas Federais

Segundo Dias (2017), o Brasil absorveu o entendimento defendido pelos organismos internacionais de que autonomia administrativa e financeira das instituições públicas pressupõe diversificar fontes de financiamento, usar recursos de forma mais eficiente, promover a redução do gasto público por aluno e, por fim, buscar eficiência, qualidade e equidade. A autonomia universitária na América Latina seria um mito, usada apenas pelos governos como "[...] um instrumento para libertar-se das responsabilidades financeiras em relação ao ensino superior" (DIAS, 2017, p. 122).

As universidades públicas federais necessitam exercer sua autonomia didáticocientífica, administrativa e de gestão financeira e patrimonial em relação àquele que a financia. Pois não há lugar para a interferência de fatores externos, a não ser os problemas sociais que devem ser levados em conta (DURHAM, 1989). Ressalta-se o entendimento de Durham (1989), segundo o qual a autonomia universitária é relativa porque não propicia liberdade absoluta e irrestrita, ou seja, as universidades federais não têm soberania, precisam prestar conta de suas atividades a outras esferas superiores. Mas o que seria mercantilização da educação superior? Estaria a autonomia direcionada para a mercantilização?

Fritsch, Jacobus e Vitelli (2020, p. 93), em revisão bibliográfica sobre a mercantilização do ensino superior, constataram que os "[...] processos de mercantilização da educação superior no mundo e no Brasil são reflexo do capitalismo globalizado, do projeto neoliberal e de um Estado a serviço desses interesses".

Para Silva Júnior e Sguissardi (2000), mercantilização manifesta-se na educação superior brasileira para "[...] aproximação com o setor produtivo, não só por causa dos ingressos orçamentários, mas também como parâmetro para o que deve ser 'produzido' pelas IES" (SILVA JÚNIOR; SGUISSARDI, 2000, p. 171).

Já para Sguissardi (2008), mercantilização da educação superior é entendida no processo em que a educação-mercadoria é transformada em objeto para os interesses privado/mercantis no aparelho do Estado, e a mercadoria-educação voltada para favorecer o capital industrial.

Nessa linha, o estudo de Severino (2008) revelou que o Estado brasileiro tem buscado reconfigurar a organização e a administração da política educacional do ensino superior nacional às exigências do modelo societário capitalista neoliberal. Ainda segundo o autor, essa política mercantil não visaria à construção do bem comum da sociedade.

Fritsch, Jacobus e Vitelli (2020) concluíram em sua revisão bibliográfica que a educação superior no País passa por um acelerado processo de mercantilização devido ao projeto neoliberal de escala global, que condiciona a educação a mercadoria, e não como bem público. As orientações dos organismos internacionais e multilaterais têm influenciado a política da educação superior pública no Brasil de modo a atender ao "projeto societário capitalista neoliberal global" (FRITSCH; JACOBUS; VITELLI, 2020, p. 98).

\section{Sistema de Educação superior do Chile, Estados Unidos da América (EUA), Portugal e Brasil}

Escolheram-se países latino-americano e desenvolvidos dos quais, de forma descritiva, apresentam-se o financiamento e a mercantilização da educação superior pública. 
A Captação de Recursos Próprios pelas Universidades Públicas Federais

Desde a década de 1990, governos brasileiros buscam implementar a gestão econômica neoliberal baseada nas ideias da "regulação/desregulação" como prática de gestão, inclusive com impactos para o financiamento da educação como um todo (DAVIES, 2016; PUELLO-SOCARRAS, 2021, p. 42; SCHLEGEL, 2021). Assim, com o propósito de realizar as análises e as comparações entre o caso brasileiro, países latino-americano e desenvolvidos, optou-se por Chile, EUA e Portugal, os quais também, como o governo brasileiro, à época da elaboração desse artigo, defendiam o neoliberalismo como a prática de seus governos.

\section{Sistema de Educação superior e seu financiamento no Chile}

Desde a reforma da educação superior de 1981, o sistema de educação superior do Chile é dividido em três modelos de instituições de ensino superior: universidades, centros de formação técnica e institutos profissionais, sendo que os cursos de pós-graduação só são oferecidos pelas universidades.

Ao analisar o financiamento da educação superior no Chile, Donoso Díaz (2005) afirma que:

Desde o final da década de 1970 as autoridades assumiram sem contrapeso 'o mercado' como a política econômica do país, incluindo todos os setores (exceto a defesa). Como consequência, o Estado reduziu sua influência no setor educacional e passou a financiar a ação de setores privados como executores de suas políticas (DONOSO DÍAZ, 2005, p. 53).

O ensino superior chileno em grande parte é privatizado e funciona com bases em princípios de livre mercado. O sistema de admissão para acesso às universidades do Estado e privadas é unificado. A Universidade de Chile concebe e corrige os exames, mas a administração desse sistema é de competência do Ministério da Educação chileno. Contudo, para Donoso Díaz (2005, p. 54), ocorreu que:

A vinculação do financiamento das escolas aos resultados do sistema de seleção para o ingresso nas universidades, - Prova de Capacitação Acadêmica (PCA) e, atualmente, Prova de Seleção Universitária (PSU). Isso gerou distorções nos critérios de admissão que até hoje não se conseguiu solucionar.

O sistema de ensino superior chileno compõe-se de 65 instituições congregadas em dois blocos, sendo o Conselho de Reitores formado pelas antigas e de maior tradição (16 estaduais e 9 particulares), que "recebem a maior parte do financiamento estatal", e o segundo bloco constitui o grupo "[...] extra conselho - que incluem as universidades privadas, criadas a partir de 1981, e que têm acesso a fundos públicos específicos" (DONOSO DÍAZ, 2005, p. $54)$.

Donoso Díaz (2005) aponta que o sistema universitário chileno foi modificado com a reforma neoliberal de 1981, do modelo de financiamento de oferta com ação direta do Estado para o modelo de financiamento por demanda. Assim, o Estado "[...] financia sob igual modelo seus dezesseis centros, inclusive nove universidades particulares, que fazem parte do Conselho de Reitores" (DONOSO DÍAZ, 2005, p. 54).

Segundo diretrizes da política neoliberal empregada no Chile, instituições de ensino superior privado não podem ter financiamento direto do Estado, no entanto, o Estado chileno financia seis universidades privadas, sendo quatro católicas e duas laicas, com a justificativa de que cumprem função pública. 
A Captação de Recursos Próprios pelas Universidades Públicas Federais

Para cursar o ensino superior no Chile, os universitários podem escolher pelo crédito do Estado, no qual a mensalidade jamais pode ultrapassar $5 \%$ do salário ganho. Em caso de não pagamento em 20 anos por falta de condições financeira, o credor perdoa a dívida. Outra opção seria pelo crédito com aval do Estado, cobrado por bancos privados. Nessa modalidade não há perdão da dívida, o valor cobrado pode superar os $5 \%$ do salário e a taxa de juros é bem mais elevada. No entendimento de Donoso Díaz (2005, p. 57) "[...] as taxas pagas pelos estudantes (matrículas e mensalidades) transformaram-se em uma importante fonte de financiamento".

No entanto, constata-se uma fragilidade para disponibilidade de um mercado de crédito de massa para financiamento da educação superior aos universitários. Os sistemas bancários que visam ao lucro alistam como riscos a "[...] incerteza acerca do término bem-sucedido dos estudos e pelas possibilidades de recuperação do crédito outorgado, dada a dificuldade de poder sustentar irrefutavelmente o emprego futuro dos que concluíram o curso" (DONOSO DÍAZ, 2005, p. 59).

O sistema de educação superior chileno, ao aplicar a lógica mercantil, tem provocado a privatização das universidades públicas, que a cada ano dependem cada vez mais de recursos financeiros do setor privado. Já as universidades privadas, em movimento contrário, buscam financiamento público do Estado como fonte de recursos (DONOSO DÍAZ, 2005).

No Chile há o denominado Acordo de Desempenho, que consiste num contrato entre a universidade e o Estado, no qual um compromisso sobre resultados a serem alcançados é fixado, com o objetivo de propiciar transferência de recursos públicos às universidades que alcancem ao máximo a eficácia e eficiência nos gastos públicos, alinhar as instituições ao contexto nacional e, por fim, promover a accountability nas universidades públicas (REICH et al., 2011).

Essa forma de financiamento estatal do Chile para instituições de ensino superior foi implementada na Nova Gestão Pública em 1998, desse modo o Estado chileno adotou a utilização de instrumentos de avaliação de desempenho associados a incentivos econômicos para as universidades. Essa política visou incentivar as universidades a buscarem alcançar resultados de produção acadêmica e metas de conclusão de alunos para terem acesso aos incentivos econômicos do governo central. O objetivo geral desse instrumento de acordo de desempenho foi atingir e promover a responsabilização das universidades que recebem recursos do Estado chileno (REICH et al., 2011; ARANEDA-GUIRRIMAN; PEDRAJA-REJAS, 2016).

A política educacional chilena pretende que as universidades tenham gestão institucional com vistas à eficiência e à eficácia dos recursos financeiros repassados pelo Estado, bem como responsabilização na aplicação das verbas recebidas do governo central. Desse modo, a eficiência econômica e resultados alcançados seriam um indicador da gestão dentro das universidades que garantiriam a qualidade de seu trabalho institucional e acesso aos incentivos educacionais (RODRÍGUEZ PONCE et al., 2011).

Nesse contexto, as universidades públicas chilenas buscam atingir uma série de indicadores de desempenho como resposta às políticas de responsabilização definidas pelo Estado, que, por sua vez, fiscaliza a violação de contrato (RUTHERFORD; RABOVSKY, 2014). A mercantilização da educação superior chilena é evidenciada de diversas maneiras, 
A Captação de Recursos Próprios pelas Universidades Públicas Federais

dentre elas a adoção de mensalidades, taxas, desregulamentação do direito social à educação, transformação do ensino superior à forma de mercadoria e assim por diante.

Para concluir, Donoso Díaz (2005, p. 62) afirma que a visão neoliberal do Estado não se atém aos princípios da equidade e às raízes históricos-sociais que dificultam o acesso à educação superior às massas da sociedade, e que, por isso, é imprescindível que "o Estado tenha suas próprias universidades e as financie devidamente".

\title{
A educação superior e o seu financiamento nos EUA
}

Entre 1862 do século XIX e 1900 do século XX configurou-se o sistema de educação superior dos EUA. Segundo Ribeiro (2016, p. 77), a "[...] educação superior dos EUA sofreu uma metamorfose, escapando do controle eclesiástico e submetendo-se ao controle da grande empresa que lhe imprimiu características até então exclusivas do mundo produtivo".

Para Ribeiro (2016), o financiamento das universidades americanas contou com o financiamento público do governo central, que doou terras para a geração de recursos que permitissem a estruturação de universidades em todos os estados dos EUA. Apesar de participação de recursos do governo federal, as universidades americanas sempre foram norteadas a buscarem fontes de recursos adicionais.

Nessa linha, Ribeiro (2016, p. 82) afirma que:

A partir de 1862 o Morril Act e leis suplementares vieram garantir o financiamento da educação superior com fundos da União, estimulando ainda uma maior participação dos governos locais no financiamento das universidades estaduais. Em Indiana os fundos levantados com a venda das terras, somados a doações realizadas por John Purdue, contribuíram para a criação de um college agrícola, mais tarde transformado na Purdue University.

As universidades dos EUA passaram a receber recursos financeiros de fundos, doações, contribuições de ex-alunos e ações filantrópicas como forma de financiamento. A esse respeito, Ribeiro (2016, p. 87) revelou que:

Em Yale foi criado o Yale Alumni Fund, que injetou recursos significativos no orçamento da instituição. Já em Harvard a contribuição de ex-alunos tornou-se uma fonte permanente de recursos. A University of Chicago foi uma das instituições mais beneficiadas por ações filantrópicas individuais.

Evidencia-se que nos EUA emergiram as fundações privadas no campo da educação superior, ficando responsáveis por uma espécie de filantropia educacional no ensino superior. Ribeiro (2016, p. 89) afirma que:

\begin{abstract}
A filantropia assumiu, mediante a ação das fundações que se constituíram como agências educacionais, um caráter empresarial. Dessas agências, a Carnegie Foundation for the Advancement of Teaching - CFAT - e a General Education Board GEB - foram as mais importantes como canais de mediação entre as instituições de educação superior e as grandes empresas.
\end{abstract}

Desse modo, os aportes de recursos oriundos dessa fonte de arrecadação eram disputados pelas universidades americanas, pois conferiam mais verbas e prestígio para as instituições e docentes da educação superior americana. Contudo, para Ribeiro (2016), a entrada desses recursos financeiros culminou no fato de que "[...] padrões, ideais e 
A Captação de Recursos Próprios pelas Universidades Públicas Federais

procedimentos próprios da grande empresa passaram então a permear a vida acadêmica, afetando o seu pessoal e a sua rotina de ensino" (RIBEIRO, 2016, p. 90).

Portanto, as universidades norte-americanas contam com o financiamento do governo federal, estadual e local. Apesar da participação desses recursos, as universidades americanas sempre foram norteadas a buscarem fontes de recursos adicionais (ORTAGUS et al., 2020). Esse país é composto por 50 estados e cada um deles possui sua própria maneira de financiar a educação superior (DOUGHERTY; REDDY, 2013).

Em 2010, 10 estados entre os 50 estados federados dos EUA adotaram o processo de desenvolvimento da política de financiamento baseada no desempenho (SNYDER, 2015). Contudo, no ano de 2015, esse país tinha aproximadamente 30 estados com políticas financiamento baseadas no desempenho, que vinculam as dotações aos resultados, como horas de crédito ganhas, taxas de graduação e realização educacional entre grupos historicamente sub-representados (ROSINGER et al., 2020).

O financiamento baseado no desempenho tem sido utilizado em quase todos os estados nos EUA, uma totalidade de 41 dentre os 50 federados. Isso evidencia que as universidades públicas americanas buscam nesse programa de financiamento, baseada no desempenho, uma das maneiras para ampliar a arrecadação de recursos para seu financiamento.

No estado de Tennessee, por exemplo, o financiamento baseado em resultados fez com que uma instituição passasse a oferecer programas de curto prazo e concedesse mais de 500 certificados em um ano (HU; VILLARREAL, 2018). Tudo isso com o objetivo de ter acesso a um incentivo econômico do governo federal.

Isso provocou, segundo análise de Ribeiro (2016, p. 90), a "mercantilização" das instituições de ensino superior dos EUA, que passaram a valorizar as diretrizes empresariais em detrimento do objetivo acadêmico. Conclui-se que a educação superior americana aderiu e focou no padrão empresarial, que diferenciou seu sistema em relação a outros países.

\section{O financiamento da educação superior em Portugal}

Para Cerdeira (2008), depois dos anos de 1990, vários governos portugueses empenharam-se em estabelecer novas formas de financiamento para as IES, a fim de reduzir a obrigação do Estado português de repassar recursos financeiros para a modalidade de educação superior.

A política de austeridade de repasse de recursos financeiros no Estado português para o financiamento do ensino superior se deu quando os governos promoveram políticas de incentivo de racionalização dos recursos humanos, fixaram teto para a contratação de docente paras as universidades e estimularam as arrecadações de receitas de fontes próprias pelas instituições de ensino superior para suplementarem as verbas financeiras para custeio de seu funcionamento (CERDEIRA, 2008).

Para Cerdeira (2008), a aprovação em Portugal de políticas como cobrança de mensalidades pelos estudantes das universidades públicas, a partir do ano de 1992, passaram de insignificantes montantes, para o total global do orçamento das IES, para indispensáveis para manter o funcionamento dessas instituições. Nessa linha, Cerdeira (2008, p. 2) assevera que a afetação dos recursos públicos do Estado português foi compensada pela: 
A Captação de Recursos Próprios pelas Universidades Públicas Federais

Contribuição das receitas arrecadadas através das propinas cobradas aos estudantes, as quais de início tinham pouca importância no conjunto dos recursos das instituições, mas que acabaram por assumir um papel significativo, sendo atualmente uma parte importante e imprescindível do orçamento das universidades e dos institutos politécnicos públicos, não só pelo seu próprio valor, mas sobretudo pelo abrandamento ou diminuição do esforço público.

As arrecadações de recursos próprios pelas universidades públicas portuguesas assumiram papel preponderante para financiar as instituições ensino superior públicas daquele país. Para Cerdeira (2008), as austeridades financeiras dos governos portugueses forçaram as IES a buscarem outras fontes de receitas para garantir seu funcionamento. Cerdeira $(2008$, p. 9$)$ apresentou quatro motivos utilizados pelos governos portugueses para adotar essa política:

Aumento na escassez das receitas públicas; pressão crescente da opinião pública para o financiamento prioritário para outros sectores (ensinos básico e secundário, saúde, justiça, etc.); uma tendência para a liberalização e para a acentuação do mercado como forma de regulação da economia, emergindo de forma clara políticas de privatização do ensino superior.

Ainda segundo Cerdeira (2008), quando o Estado português diminuiu o aporte de repasse financeiro às universidades públicas do país, constrangeram-nas a:

Complementar as receitas recebidas por via governamental, não apenas com as receitas cobradas das propinas, mas também recorrendo a outras atividades ditas empreendedoras, como sejam a venda e prestação de serviços, a venda ou aluguer das suas infraestruturas, a captação de subsídios e de contratos, e de apoios e ofertas de antigos alunos, cuja existência e dimensão foi ganhando um peso considerável e muitas vezes vital para a própria sobrevivência das instituições (CERDEIRA, 2008, p. 9).

Nesse sentido, a diminuição do aporte financeiro do governo fez as instituições portuguesas de ensino superior buscarem ampliar seus recursos. Para tal, tiveram que mercantilizar serviços como aluguel ou venda de espaços, prestação de serviços e outros. Tudo isso materializou a política incentivada desde o final do século $X X$, identificada como "[...] fomentadoras da diversificação de captação de receitas por parte das instituições de ensino superior em todo o mundo" (CERDEIRA, 2008, p. 84).

$\mathrm{Na}$ análise de Cerdeira (2008, p. 248), as despesas das instituições de ensino superior portuguesas são:

Suportada pelo orçamento de Estado, tendo as Receitas Próprias um peso menor. Em 1989, após a saída da Lei da Autonomia das Universidades, verificava-se que o Orçamento de Estado suportava cerca de $95 \%$ das despesas do ensino superior, restando apenas uma fatia de $5 \%$ para as Receitas Próprias. O valor de receitas provinha na sua maior parte da 'Venda de Bens e Serviços' e 'Outros Subsídios'.

Assim, Cerdeira $(2008,281)$ exemplifica afirmando que:

Em 2006, cerca de $31 \%$ da despesa realizada pelas universidades teve financiamento próprio, enquanto nos institutos politécnicos e nas escolas de enfermagem esse valor se ficava pelos $26 \%$ e $22 \%$, respectivamente. Em termos globais, em 2006, orçamento de funcionamento representou $67 \%$ do valor gasto, as Receitas Próprias $29 \%$ e os Investimentos do Plano 4\% (PIDDAC, fundos comunitários e recursos próprios. 
A Captação de Recursos Próprios pelas Universidades Públicas Federais

Fica evidente que a política de cobrança de mensalidades e a busca no mercado por formas de financiamento pelas universidades públicas decorrem da redução do Estado português no financiamento das universidades públicas, seguindo a tendência mundial de mercantilização do ensino superior público (CERDEIRA, 2008).

\section{O financiamento da educação superior no Brasil}

O sistema universitário brasileiro tem em sua composição 69 universidades públicas federais mantidas com recursos do fundo público. Este depende do comportamento da política macroeconômica, da arrecadação de impostos pela União, do resultado primário e da política fiscal (VELOSO; MARQUES, 2005).

O financiamento público da educação é garantido pela CF/88, conforme disposto no art. 212:

A União aplicará, anualmente, nunca menos de dezoito e os Estados, o Distrito Federal e os Municípios vinte e cinco por cento, no mínimo, da receita resultante de impostos, compreendida a proveniente de transferências, na manutenção e desenvolvimento do ensino (BRASIL, 1988).

O financiamento da manutenção das universidades federais é de competência da União, como fixado no art. 55 da Lei $n^{\circ} 9.394$ de 1996, que "[...] caberá a União assegurar, anualmente, em seu orçamento geral, recursos suficientes para a manutenção e desenvolvimento das instituições de educação superior por ela mantidas" (BRASIL, 1996).

Isso significa que as verbas destinadas à educação passaram a ter vinculação de receitas, ou seja, recursos financeiros oriundos de impostos foram destinados aos fins específicos da educação. Para Sena (2002, p. 17):

Os meios econômico-orçamentários dos poderes executivos nas três esferas são ideologicamente contra a vinculação de recursos. Esta posição cristalizou-se no art. 167, IV da Constituição, que veda as vinculações, tolerando algumas exceções, entre as quais a vinculação à manutenção e desenvolvimento do ensino.

O financiamento das universidades públicas federais ocorre por meio do Tesouro Nacional. As suas despesas, excluindo pessoal, foram classificadas como discricionárias ou não obrigatórias, portanto, o limite orçamentário para essas despesas depende do volume de recursos disponíveis, dentro dos parâmetros econômicos e da meta de resultado fiscal.

As receitas oriundas do Tesouro Nacional correspondem a $86,3 \%$ do orçamento das universidades federais destinadas ao custeio e capital e, os recursos oriundos de fontes próprias, resultantes da cobrança de taxas, de convênios e contratos, chamados de receitas próprias $^{6}$, correspondem a $10,61 \%$ das receitas das universidades federais; a outra fonte seria gerenciada pelas fundações de apoio (AMARAL; PINTO, 2010).

O processo de contingenciamento de receitas orçamentárias impactou todos os poderes, incluindo os recursos do Poder Executivo, que tem o dever de repassar recursos às universidades públicas federais. Segundo Lopreato (2006), a partir de 1990 as novas regras

6 Receitas próprias seriam receitas provenientes do esforço de arrecadação de cada órgão, isto é, receitas que o órgão tem a competência legal de prever e arrecadar (BRASIL, 2007). 
A Captação de Recursos Próprios pelas Universidades Públicas Federais

fiscais estabelecidas passaram a conduzir as contas públicas com o superávit primário ${ }^{7}$, por meio da aprovação da Lei de Responsabilidade Fiscal.

Para Lopreato (2006, p. 215), a meta de superávit primário passou a influenciar e controlar as despesas discricionárias, pois:

O superávit ganhou, assim, um caráter compulsório e, principalmente, as despesas discricionárias que compõem o orçamento de custeio e capital passaram a atuar como um resíduo, isto é, devem se ajustar sempre que as condições de receita não se concretizarem ou o valor do superávit ficar abaixo do fixado originalmente.

A Tabela 1 aponta que, de 2016 em diante, houve um decréscimo na execução das despesas discricionárias financiadas pela fonte tesouro oriundas da Secretaria do Tesouro Nacional (STN), tanto para custeio (pagamento de conta água, luz, papel, etc.) como para capital (compra de equipamentos). Esse fato permite a interpretação de que o Estado brasileiro vem se eximindo da responsabilidade de garantir financiamento suficiente às instituições públicas federais. A execução das despesas discricionárias diminuiu e o número de universidades federais aumentou, em 2016 eram 63 e, em 2020, havia 69 universidades federais. Isso fez com que os recursos demonstrados na Tabela 1 tenham sido repartidos entre todas as universidades federais por matriz fixadas pela Secretaria de Educação Superior do Ministério da Educação.

A disputa por recursos discricionários para financiar despesas de manutenção, pesquisa, extensão, a cada ano, faz com que as universidades federais busquem ampliar suas receitas com recursos fora da esfera estatal. A Tabela 1 mostra a execução das despesas discricionárias das universidades federais entre 2010 e 2020

Tabela 1 - Despesas discricionárias das universidades federais entre 2010 e 2020

Valores em bilhões de reais; Valores atualizados de janeiro de cada ano a março de 2021 pelo índice IPCA (IBGE)

\begin{tabular}{c|c|c|cc}
\multirow{2}{*}{ Ano } & \multicolumn{2}{c}{ Liquidado } & \multicolumn{2}{c}{ Pago } \\
\cline { 2 - 5 } & Custeio & Capital & Custeio & Capital \\
\hline 2010 & 4,63 & 0,96 & 4,50 & 0,87 \\
\hline 2011 & 5,04 & 1,13 & 4,93 & 1,08 \\
\hline 2012 & 5,54 & 1,08 & 5,45 & 1,03 \\
\hline 2013 & 7,11 & 1,13 & 6,84 & 1,03 \\
\hline 2014 & 7,04 & 1,43 & 6,50 & 1,36 \\
\hline 2015 & 6,84 & 0,91 & 6,42 & 0,71 \\
\hline 2016 & 6,59 & 0,67 & 6,50 & 0,65 \\
\hline 2017 & 5,86 & 0,39 & 5,77 & 0,38 \\
\hline 2018 & 5,85 & 0,25 & 5,75 & 0,24 \\
\hline 2019 & 5,48 & 0,15 & 5,37 & 0,14 \\
\hline 2020 & 4,32 & 0,17 & 4,22 & 0,17 \\
\hline
\end{tabular}

7 O superávit consiste no resultado positivo entre receitas e despesas do governo, excetuando gastos com pagamento de juros. Ou a receita é superior à despesa ou se há aumento da arrecadação ou decréscimo dos gastos (BRASIL, 2007). 
A Tabela 1 mostra que de 2016 para 2020 a execução das despesas discricionários da fonte Tesouro diminuiu em $\mathrm{R} \$ 2,27$ bilhões, queda de 34,4\%. Quanto à despesa paga em custeio, houve queda de $R \$ 2,28$ bilhões nesse período, o que equivale a $35 \%$. Em análise das despesas de capital, a situação, tanto em despesas liquidadas e pagas, é mais crítica, pois caiu $R \$ 0,50$ bilhões e 0,48 bilhões respectivamente. O que representa diminuição em $74,6 \%$ em despesas liquidadas e $73,8 \%$ em despesas pagas.

Isso confirma a análise de Fávero e Bechi (2017) de escassez de recursos da esfera governamental destinados ao financiamento das universidades públicas federais, em especial recursos para suprir as despesas discricionárias, o que induziria essas instituições a buscarem novas formas de captação de recursos junto ao setor privado, com o fim de complementar o aporte de recursos federais. Essa forma de captação passou a ser considerada estratégia de sobrevivência para tais instituições (FÁVERO; BECHI, 2017).

Já a Tabela 2 evidencia como o Estado brasileiro tem financiado as despesas obrigatórias das universidades federais entre 2010 e 2020. Segundo Carvalho (2011), em 2002, devido a problemas de ordem econômica, ocorreu "[...] arrocho salarial, controle de verbas de custeio com saúde, educação e outros, bem como a redução dos gastos com investimentos" (CARVALHO, 2011, p. 178). Entre 2013 e 2017, no entendimento de Carvalho (2011), houve aumento significativo das despesas obrigatórias decorrentes do desafio do governo federal de estimular o crescimento do Produto Interno Bruto e melhorar a inclusão social e da distribuição de renda. Esse fato é constatado na Tabela 2, nas despesas de pessoal e encargos sociais, nas despesas liquidadas e pagas entre 2010 e 2020.

Tabela 2 - Execução das despesas obrigatórias das universidades federais entre 2010 e 2020

Valores em bilhões de reais; Valores atualizados de janeiro de cada ano a março de 2021 pelo índice IPCA (IBGE)

\begin{tabular}{c|c|c|c|c}
\multirow{2}{*}{ Ano } & \multicolumn{2}{|c}{ Liquidado } & \multicolumn{2}{c}{ Pago } \\
\cline { 2 - 5 } & Custeio & $\begin{array}{c}\text { Pessoal e } \\
\text { Encargos sociais }\end{array}$ & Custeio & $\begin{array}{c}\text { Pessoal e Encargos } \\
\text { sociais }\end{array}$ \\
\hline 2010 & 0,19 & 0,48 & 0,19 & 0,48 \\
\hline 2011 & 0,08 & 0,39 & 0,07 & 0,39 \\
\hline 2012 & 0,08 & 0,30 & 0,08 & 0,30 \\
\hline 2013 & 2,04 & 39,17 & 2,03 & 39,01 \\
\hline 2014 & 2,02 & 40,86 & 2,08 & 41,53 \\
\hline 2015 & 1,96 & 43,05 & 1,96 & 43,04 \\
\hline 2016 & 2,32 & 42,26 & 2,31 & 42,21 \\
\hline 2017 & 2,19 & 44,77 & 2,18 & 44,73 \\
\hline 2018 & 2,15 & 45,47 & 1,98 & 41,94 \\
\hline 2019 & 2,09 & 46,30 & 1,89 & 42,78 \\
\hline 2020 & 2,19 & 43,85 & 2,05 & 41,33 \\
\hline & Fonte: Elaborado pelos autores com base no Siafi. \\
\hline
\end{tabular}

Observa-se, na Tabela 2, a diminuição das despesas com pessoal em despesas liquidadas e pagas entre o ano de maior gasto, que foi 2017, para 2020. As despesas 
A Captação de Recursos Próprios pelas Universidades Públicas Federais

obrigatórias liquidadas e pagas em custeio tiveram seu ápice em 2016, com $R \$ 2,32$ bilhões, para $\mathrm{R} \$ 2,19$ bilhões em 2020 , queda $5,6 \%$.

\section{Comparativo entre Brasil, Chile, EUA e Portugal}

O Brasil possui um sistema de financiamento para educação superior diferente do Chile, EUA e Portugal. No Chile, a educação superior é privatizada e funciona com bases em princípios de livre mercado, financiamento por demanda e o sistema de admissão para as universidades públicas e privadas são unificados. O Estado chileno realiza a cobrança de matrículas e mensalidades dos alunos para custear parte do financiamento da educação superior. As universidades públicas chilenas dependem significativamente de verbas financeiras do setor privado. O sistema de educação superior chileno, ao cobrar mensalidades e matrículas, dificulta o acesso da maioria da população a essa forma de ensino (RODRÍGUEZ PONCE et al., 2011).

As universidades dos EUA adotaram como financiamento recursos financeiros oriundos de fundos, doações, contribuições de ex-alunos e ações de entidades filantrópicas para as instituições de ensino superior. Implementou ainda o financiamento baseado em desempenho, no qual as universidades, para receber incentivos e recursos do governo central, necessitam atingir metas e objetivos. O desempenho não é medido pela qualidade, mas sim pela quantidade. O que provoca a busca incessante por emissão de certificados e alunos que possam arcar com as mensalidades. O sistema de educação superior é restrito aos alunos que podem pagar pela educação superior.

Portugal adotou a cobrança de mensalidades e arrecadação de fontes próprias para manter as instituições de ensino superior. O governo português diminuiu o repasse financeiro para as universidades, forçando essas instituições a buscar outras formas de financiamento. O sistema de educação superior português tem implementado a mercantilização no ensino público.

As universidades públicas federais brasileiras têm seu financiamento custeado por recursos públicos, em torno de $86,3 \%$ pela fonte tesouro do governo federal. Porém, vem sendo implementado um processo de mercantilização da educação superior, pois as universidades públicas federais negociam a mercadoria educação por meio de captação de receitas de fontes próprias e fundações de apoio, que já representam em torno de 10,61\% das suas receitas. Vale mencionar que muitas universidades públicas federais buscam atender às demandas de empresas para formar pessoas que possam garantir a produtividade (MINTO, 2008; AMARAL; PINTO, 2010).

A educação superior no Brasil passa pelo momento de incentivo de autofinanciamento, prestação de serviço, a equivalência da educação à mercadoria; retirada da responsabilidade do Estado a execução de políticas públicas baseada no neoliberalismo.

\section{A gestão da arrecadação de receitas próprias das universidades federais brasileiras}

As receitas próprias compõem o orçamento das universidades públicas federais, para tanto, essas instituições prestam serviços e cobram taxas; utilizam patrimônio público em atividades econômicas destinadas ao mercado. Para Boaventura de Sousa Santos (2004, p. 
A Captação de Recursos Próprios pelas Universidades Públicas Federais

92), "[...] o fato de a universidade pública ser induzida a ultrapassar a crise financeira mediante a geração de receitas próprias, consiste no primeiro nível de mercantilização".

Para Fávero e Bechi (2017), a arrecadação de recursos por meio de receitas próprias e fundações de apoio junto ao setor privado soma-se às receitas da esfera governamental e compõem a receita orçamentária total das universidades federais. Essa organização orçamentária de captação de recursos públicos e privados ao orçamento das universidades federais no Brasil se deve aos recorrentes cortes orçamentários para as despesas discricionárias, pois as receitas do Tesouro Nacional se destinam quase exclusivamente às despesas obrigatórias para pagamento de pessoal e encargos sociais, conforme descrito na Tabela 2.

Outro fator a ser questionado está na ausência de igualdade e de capacidade entre as universidades federais de captar recursos de fontes próprias, seja com esforço próprio ou mediante fundações de apoio. As arrecadações das 69 universidades federais foram demonstradas na Tabela 3.

Tabela 3 - Ciclo orçamentário das receitas próprias das universidades federais entre 2010 e 2020

Valores em bilhões de reais; Valores atualizados de janeiro de cada ano a março de 2021 pelo índice IPCA(IBGE)

\begin{tabular}{|c|c|c|c|c|c|c|c|c|}
\hline \multicolumn{9}{|c|}{ Receita de Fonte própria } \\
\hline \multirow{2}{*}{ Ano } & \multicolumn{2}{|c|}{ Dotação Inicial na LOA } & \multicolumn{2}{|c|}{ Empenho } & \multicolumn{2}{|c|}{ Liquidado } & \multicolumn{2}{|c|}{ Pago } \\
\hline & Custeio & Capital & Custeio & Capital & Custeio & Capital & Custeio & Capital \\
\hline 2010 & 1,54 & 0,44 & 1,31 & 0,25 & 1,08 & 0,12 & 1,07 & 0,11 \\
\hline 2011 & 1,63 & 0,44 & 1,15 & 0,17 & 1,01 & 0,08 & 0,99 & 0,08 \\
\hline 2012 & 1,66 & 0,44 & 1,32 & 0,21 & 1,09 & 0,09 & 1,08 & 0,09 \\
\hline 2013 & 1,68 & 0,42 & 1,81 & 0,22 & 1,54 & 0,08 & 1,51 & 0,08 \\
\hline 2014 & 1,73 & 0,34 & 1,42 & 0,14 & 1,42 & 0,07 & 1,42 & 0,07 \\
\hline 2015 & 1,55 & 0,30 & 1,09 & 0,13 & 0,92 & 0,06 & 0,91 & 0,06 \\
\hline 2016 & 1,17 & 0,20 & 0,87 & 0,08 & 0,68 & 0,03 & 0,66 & 0,03 \\
\hline 2017 & 1,03 & 0,18 & 0,81 & 0,11 & 0,63 & 0,03 & 0,61 & 0,03 \\
\hline 2018 & 0,88 & 0,18 & 0,80 & 0,12 & 0,62 & 0,03 & 0,61 & 0,03 \\
\hline 2019 & 0,89 & 0,13 & 0,75 & 0,12 & 0,56 & 0,04 & 0,55 & 0,04 \\
\hline 2020 & 0,80 & 0,11 & 0,48 & 0,11 & 0,31 & 0,02 & 0,30 & 0,02 \\
\hline
\end{tabular}

Fonte: Elaborado pelos autores com base na LOA e Siafi.

A Tabela 3 mostra que a gestão estratégica e financeira da arrecadação de receitas próprias das universidades públicas federais teve o ano de 2014 como o ano de maior dotação de crédito em custeio na LOA, com R $\$ 1,73$ bilhões; e, o ano de 2020 , o de menor, com $\mathrm{R} \$$ 800 milhões, ou seja, queda de $53,7 \%$. O ciclo orçamentário de empenho, liquidado e pago, seguiu a mesma vertente da dotação de crédito na LOA; o ano de 2014, em custeio, teve respectivamente dotações de $R$ \$1,42 bilhões, $R$ \$ 1,27 bilhões, 1,42 bilhões e $R$ \$ 1,42 bilhões.

Os recursos de capital, que são bem disputados pelas universidades federais, em 2013, tiveram como despesa liquidada e paga em capital de fontes próprias o maior valor na série histórica da Tabela 3. Já as despesas discricionárias liquidadas e pagas na fonte tesouro, no ano de 2014, conforme Tabela 1, foram os maiores valores de capital nas fontes próprias e representaram $6,29 \%$ do maior executado em capital na fonte própria de fonte tesouro. 
A Tabela 3 evidencia uma redução no ciclo orçamentário das despesas executadas com recursos angariados com esforços próprios, pela via intraorçamentária na LOA, porque muito provavelmente as universidades federais têm usado as fundações de apoio para arrecadar de maneira extraorçamentária, sem o controle do governo federal. Para essa suposição, usouse como exemplo a Universidade Federal do Rio de Janeiro, que arrecadou, segundo dados da Fundação COPPETEC ${ }^{8}$, os valores da Tabela 4.

Tabela 4 - Receita Bruta da Fundação COPPETEC entre 2010 e 2020

Valores em bilhões de reais; Valores atualizados de janeiro de cada ano a março de 2021 pelo índice IPCA (IBGE)

\begin{tabular}{rcccc} 
Ano & Contrato & Convênio & Doações & Total \\
\hline 2010 & 0,221 & 0,277 & 0,277 & 0,776 \\
\hline 2011 & 0,219 & 0,251 & 0,00002 & 0,471 \\
\hline 2012 & 0,222 & 0,292 & 0,00002 & 0,514 \\
\hline 2013 & 0,218 & 0,322 & 0,00001 & 0,541 \\
\hline 2014 & 0,185 & 0,291 & 0,00015 & 0,476 \\
\hline 2015 & 0,170 & 0,205 & 0,00040 & 0,376 \\
\hline 2016 & 0,131 & 0,210 & 0,00015 & 0,341 \\
\hline 2017 & 0,110 & 0,238 & 0,00020 & 0,348 \\
\hline 2018 & 0,092 & 0,359 & 0,00042 & 0,451 \\
\hline 2019 & 0,125 & 0,353 & 0,00004 & 0,479 \\
\hline 2020 & 0,079 & 0,226 & 0,005 & 0,311 \\
\hline & Total Geral & & $\mathbf{5 , 0 8 3}$ \\
\hline
\end{tabular}

Fonte: Dados disponibilizados pela Fundação COPPETEC.

Essa única fundação, entre as 98 afiliadas ao Conselho Nacional de Apoio às Instituições de Ensino Superior (CONFIES) ${ }^{9}$, arrecadou, entre 2010 e 2020, o total de R\$ 5,083 bilhões de reais, valor que é quase oito vezes maior que o valor pago em capital por todas as 69 universidades federais e significou aproximadamente $52,3 \%$ de todo o valor pago em capital por todas as universidades federais, conforme Tabela 3. Isso comprova que algumas universidades federais têm usado as fundações de apoio para arrecadar, ou seja, têm mercantilizado o ensino e a pesquisa ao seu modo.

\section{Conclusão}

As universidades públicas federais são um direito constitucional para a sociedade brasileira. Chile, EUA e Portugal possuem sistemas de financiamento diferentes em relação ao Brasil, contudo, ao compararmos o caso brasileiro e os sistemas universitários desses países, fica evidente que adotaram o neoliberalismo e a mercantilização do ensino superior por meio de cobrança de taxas, matrículas e mensalidades no ensino superior público. Esse fato dificulta o acesso ao ensino superior aos cidadãos desses países, que não podem financiar sua educação superior.

Há uma tentativa no Brasil de romper com o dever do Estado de prover e financiar a educação superior, as constantes diminuições de recursos para as despesas discricionárias

8 Essa Fundação divulga dados em http://www.coppetec.coppe.ufrj.br/site/transparencia/receitas.php.

9 Para maiores informações, verificar: http://confies.org.br/institucional/. 
A Captação de Recursos Próprios pelas Universidades Públicas Federais

em custeio e capital, no período entre 2010 e 2020, conforme a Tabela 1, são uma prova desse fato. A busca das universidades federais e fundações de apoio em captar fontes próprias junto ao setor privado é um passo da mercantilização do ensino superior no Brasil, pois viabiliza a utilização de servidores e espaço público a interesses privados. A gestão financeira das despesas empenhadas, liquidadas e pagas, de arrecadações de receitas próprias de prestação de serviços no exercício da autonomia das universidades federais, conforme a Tabela 3 , em si constitui-se uma maneira de mercantilização da educação superior.

A mercantilização do ensino superior tem relação com a autonomia universitária, que não é absoluta, mas a criação de fundações de apoio para dar suporte às universidades federais com o fim de possibilitar uma arrecadação extraorçamentário, fora do controle do governo federal, seria uma forma questionável do exercício de autonomia. A Tabela 3 mostrou uma diminuição da arrecadação das fontes próprias a partir de 2014. Será relevante, para contribuir para a literatura, um estudo futuro que realize um comparativo das arrecadações de fontes próprias pelas universidades federais, intraorçamentária, e as arrecadações realizadas pelas fundações de apoio, de modo extraorçamentário.

\section{Referências}

ALVES, A. M.; AZEVEDO, M. L. Fundação de apoio à universidade: uma discussão sobre o conflito entre o público e o terceiro setor. Campinas: HISTEDBR, 2006

AMARAL, N. C; PINTO, J. M. R. O financiamento das IES brasileiras em 2005: recursos públicos, privados e custo dos alunos. Série-Estudos, Campo Grande, n. 30, 2010.

ANAFINOVA, S. The role of rankings in higher education policy: Coercive and normative isomorphism in Kazakhstani higher education. Internacional Journal of Educational Development, v. 78, 2020.

ARANEDA-GUIRRIMAN, C. A; PEDRAJA-REJAS, L. M. Financiamiento por Desempeño en Chile: Análisis Conceptual de un Instrumento para la Educación Superior. Form. Univ., La Serena, v. 9, n. 3, p. 75-86, 2016.

AROCENA, R.; SUTZ, J. Universities and social innovation for global sustainable development as seen from the south. Technological forecasting and social change, v. 162, 2021.

BACHINI, N.; CHICARINO, T. S. Os métodos quantitativos, por cientistas sociais brasileiros: entrevistas com Nelson do Valle Silva e Jerônimo Muniz. Revista Sociedade e Estado, v. 33, 2018.

BELYAEVA, Z.; SCAGNELLI, S.; THOMAS, M.; CISI, M. Student perceptions of university social responsibility: A cross-national study in Italy, France and Russia. World Review of Entrepreneurship, Management and Sustainable Development, 2018.

BRASIL. Constituição da República Federativa do Brasil de 1988. Diário Oficial da União, Brasília, 1988.

BRASIL. Receitas públicas: manual de procedimentos: aplicado à União, Estados, Distrito Federal e Municípios Ministério da Fazenda. Brasília: Secretaria do Tesouro Nacional, 2007. 
A Captação de Recursos Próprios pelas Universidades Públicas Federais

CARVALHO, C. H. A. A Política Pública para a educação Superior no Brasil: ruptura e/ou continuidade. 2011. 441 f. Tese (Doutorado em Economia) - Instituto de Economia, Universidade Estadual de Campinas, Campinas, 2011.

CARVALHO, C. H. A. A mercantilização da educação superior brasileira e as estratégias de mercado das instituições lucrativas. Revista Brasileira de Educação, Rio de Janeiro, v. 18, 2013.

CERDEIRA, M. L. M. O financiamento do ensino superior português: a partilha de custos. 2008. Dissertação (Doutoramento) - Universidade de Lisboa, Faculdade de Psicologia e Ciências da Educação, Lisboa, 2008.

CONTRERAS, I.; LOZANO, S. Allocating Additional Resources to Public Universities. A DEA Bargaining Approach. Socio-Economic Planning Sciences, September 2020.

CRESWELL, J. W.; PLANO CLARK, V. L. Designing and conducting mixed methods research. 2. ed. Los Angeles: SAGE Publications, 2011.

DAVIES, W. EI Nuevo Neoliberalismo. New Left Review, v. 101, 2016.

DIAS, M. A. R. Educação Superior como bem Público Perspectivas para 0 Centenário da Reforma de Córdoba. Montevideo: Secretaria Executiva de Associação de Universidades Grupo Montevideo, 2017.

DONOSO DÍAZ, S. A reforma neoliberal da educação superior no Chile em 1981. Revista Brasileira de Ciências Sociais, São Paulo, v. 20, 2005.

DOUGHERTY, K. J.; REDDY, V. Performance funding for higher education: What are the mechanisms? What are the impacts? ASHE Higher Education Report, v. 39, p. 1-152, 2013.

DURHAM, E. R. A autonomia universitária. O princípio constitucional e suas implicações. São Paulo: NUPES-USP, 1989.

ERNSTE, $\mathrm{H}$. The international network university of the future and their local and regional impacts. In: HARDING, A.; LASKE, S.; SCOTT, A. Bright Satanic Mills: Universities, regional development and the knowledge. London: Routledge, 2007.

FÁVERO, A. A.; BECHI, D. O Financiamento da Educação Superior no Limiar Do Século XXI: O Caminho da Mercantilização da Educação. Revista Internacional de Educação Superior, Campinas, v. 3, n. 1, p. 90-113, 2017.

FÁVERO, M. L. A. Universidade do Brasil: das origens à construção. 2. ed. Rio de Janeiro: Editora UFRJ, 2010.

FERRARIS, A.; BELYAEVA, Z.; BRESCIANI, S. The role of universities in the Smart City innovation: Multistakeholder integration and engagement perspectives. Journal of Business Research, v. 119, 2020.

FRITSCH, R.; JACOBUS, A. E.; VITELLI, R. F. Diversificação, mercantilização e desempenho da educação superior brasileira. Avaliação, Sorocaba, v. 25, 2020.

GIACOMONI, J. Orçamento Público. 16. ed. São Paulo: Editora atlas, 2012. 
A Captação de Recursos Próprios pelas Universidades Públicas Federais

HSU, D. H.; HSU, P.-H.; ZHOU, T.; ZIEDONIS, A. A. Benchmarking U.S. university patent value and commercialization efforts: A new approach. Research Policy, Elsevier, v. 50, 2021.

HU, X.; VILLARREAL, P. Public tuition on the rise: Estimating effects of Louisiana's performance-based funding policy on institutional tuition levels. Research in Higher Education, v. 60, p. 636-669, 2018.

LIEFNER, I. Funding, resource allocation, and performance in higher education systems. Higher Education, Springer, v. 46, p. 469-489, 2003.

LOPREATO, F. L. C. Política fiscal: mudanças e perspectivas. In: CARNEIRO, Ricardo (Org.). A supremacia dos mercados e a política econômica do governo Lula. São Paulo: Editora UNESP, 2006.

MINAYO, M. C. S.; SANCHES, O. Quantitativo-qualitativo: oposição ou complementaridade? Cadernos de Saúde Pública, Rio de Janeiro, v. 9, 1993.

MINTO, L. W. Governo Lula e "Reforma Universitária": presença e controle do capital no ensino superior. Resenha do livro de José Rodrigues, Os Empresários e a Educação Superior (Campinas: Autores Associados, 2007). Educação \& Sociedade, Campinas, v. 29, n. 105, p. 1246-1249, set./dez. 2008.

ORTAGUS, J. C.; KELCHEN, R.; ROSINGER, K.; VOORHEES, N. Performance-Based Funding in American Higher Education: A Systematic Synthesis of the Intended and Unintended Consequences. Educational Evaluation and Policy Analysis, v. 42, n. 4, p. 520550, 2020.

PRODANOV, C. C.; FREITAS, E. C. Metodologia do trabalho Científico: Métodos e Técnicas da Pesquisa e do Trabalho Acadêmico. Novo Hamburgo: ASPEUR, 2013.

PUELLO-SOCARRAS, J. F. Novo neoliberalismo: arquitetônica estatal no capitalismo do século XXI. Revista eletrônica de administração, Porto Alegre, v. 27, 2021.

RANIERI, N. B. S.; LUTAIF, M. K. A autonomia universitária e seus percalços. Revista Eletrônica de Jornalismo Científico, Com Ciência, São Paulo, 2019.

RAUDLA, R.; KARO, E.; VALDMAA, K.; KATTEL, R. Implications of project-based funding of research on budgeting and financial management in public universities. Higher Education, v. 70, 2015.

REICH, R.; MACHUCA, F.; LÓPEZ STEFONI, D.; PRIETO, J. P.; MUSIC, J.; RODRÍGUEZPONCE, E.; YUTRONIC, J. Bases y desafíos de la aplicación de convenios de desempeño en la educación superior de Chile. Ingeniare. Revista chilena de ingeniería, v. 19, p. 08-18, 2011.

RIBEIRO, M. G. A educação superior norte-americana: gênese de um modelo. História da Educação, Santa Maria, v. 20, 2016.

RODRÍGUEZ-PONCE, E.; ARANEDA-GUIRRIMAN, C.; PEDRAJA-REJAS, L.; RODRÍGUEZPONCE, J. La Relación entre la Calidad de las Universidades y su Eficacia Económica: Un Estudio Empírico en Instituciones de Chile. Panorama Socioeconómico, v. 43, p. 79-89, 2011. 
A Captação de Recursos Próprios pelas Universidades Públicas Federais

ROSINGER, K. O.; ORTAGUS, J. C.; KELCHEN, R.; CASSELL, A.; VOORHEES, N. The landscape of performance-based funding in 2020. Informed states, 2020.

RUTHERFORD, A.; RABOVSKY, T. Evaluating Impacts of Performance Funding Policies on Student Outcomes in Higher Education. The Annals of the American Academy of Political and Social Science, v. 655, p. 185-208, 2014.

SANTOS, B. S. A universidade no século XXI: para uma reforma democrática e emancipatória da Universidade. 3. ed. São Paulo: Cortez, 2010.

SCHLEGEL, R. Impactos políticos da educação: da aposta no novo cidadão à eleição de Bolsonaro. Educação \& Sociedade, Campinas, v. 42, 2021.

SENA, P. A. União e a aplicação dos recursos vinculados à manutenção e ao desenvolvimento do ensino. Revista Brasileira de Estudos Pedagógicos, Brasília, v. 83, 2002.

SEVERINO, A. J. O ensino superior brasileiro: novas configurações e velhos desafios. Educar, Curitiba, n. 31, 2008.

SGUISSARDI, V. Modelo de expansão da educação superior no Brasil: predomínio privado/mercantil e desafios para a regulação e a formação universitária. Educação \& Sociedade, Campinas, v. 29, 2008.

SHEN, J. Universities as financing vehicles of (sub)urbanisation: the development of university towns in Shanghai. Land Use Policy, Elsevier, 2020.

SILVA JÚNIOR, J. dos R.; SGUISSARDI, V. A Educação Superior Privada no Brasil: Novos Traços de Identidade. In: SGUISSARDI, V. (Org.). Educação Superior: velhos e novos desafios. São Paulo: Xamã, 2000.

SNYDER, M. Driving better outcomes: Typology and principles to inform outcome-based funding models. 2015. Available at: http://hcmstrategists.com/wp-content/uploads/2015/07/ Driving-Outcomes-Report-final.pdf. Accessed on: 10 May 2021.

STEINER, L.; SUNDSTRÖM, A. C.; SAMMALISTO, K. An analytical model for university identity and reputation strategy work. Higher Education, v. 65, 2013.

VELOSO, J.; MARQUES, P. Recursos Próprios da UnB, o Financiamento das IFES e a Reforma da Educação Superior. Educação \& Sociedade, Campinas, v. 26, 2005.

WANG, D. Performance-based resource allocation for higher education institutions in China. Socio-Economic Planning Sciences, Elsevier, v. 65, p. 66-75, 2019.

Eduardo Ferreira da Silva Caetano é doutorando em Educação na Universidade de São Paulo, Mestre em Educação na Universidade de Brasília, Master Business Administration MBA em Administração Pública na Escola de Administração e Negócios ESAD, Bacharel em Direito no Instituto Processus de Brasília, pedagogo na Universidade de Brasília e Advogado. ORCID: http://orcid.org/0000-0003-2223-4249

E-mail: eduardofscaetano@gmail.com

Ivete Maria Barbosa Madeira Campos é doutoranda em Educação na Universidade de Brasília, Mestre em Educação na Universidade de Brasília, Master Business Administration - 
A Captação de Recursos Próprios pelas Universidades Públicas Federais

MBA em Administração Pública na Fundação Getúlio Vargas, graduada em Ciências Sociais na Universidade de Brasília.

ORCID: http://orcid.org/0000-0002-8832-7395

E-mail: ivete.campos@gmail.com

Vilma Pereira Cavalcanti é mestranda em Administração Pública pela Universidade Federal de Lavras, responsável pelas Emendas Parlamentares da Coordenação de Programação Orçamentária da Subsecretária de Planejamento e Orçamento do Ministério da Educação.

ORCID: https://orcid.org/0000-0002-1375-3795

E-mail: vilma.cavalcanti@mec.gov.br 